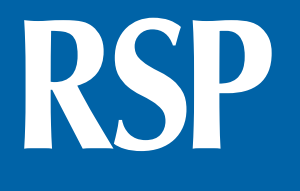

http://www.rsp.fsp.usp.br/
Revista de Saúde Pública

\title{
Restrictive measure for the commercialization of antimicrobials in Brazil: results achieved
}

\author{
Josiane Moreira da Costa' (iD, Cristiano Soares de Moura" (iD, Cristiane Aparecida Menezes de \\ Pádua"I (iD, Aline Siqueira Fogal Vegi" iD, Sérgia Maria Starling Magalhães"II (iD, Marina Barra \\ Rodrigues $^{\text {III }}$ iD, Andréia Queiroz Ribeiro ${ }^{\text {IV }}$ iD \\ I Universidade Federal de Minas Gerais. Faculdade de Farmácia. Programa de Pós-Graduação em Medicamentos \\ e Assistência Farmacêutica. Belo Horizonte, MG, Brasil \\ " McGill University. Division of Clinical Epidemiology. Department of Epidemiology. Montreal, Quebec, Canada \\ III Universidade Federal de Minas Gerais. Faculdade de Farmácia. Departamento de Farmácia Social. Belo \\ Horizonte, MG, Brasil \\ Iv Universidade Federal de Viçosa. Centro de Ciências Biológicas e da Saúde. Departamento de Nutrição e \\ Saúde. Viçosa, MG, Brasil
}

\section{ABSTRACT}

OBJECTIVE: To assess whether the incidence of hospital infection by a resistant microorganism decreased after the implementation of the restrictive measure of the National Health Surveillance Agency for the commercialization of antimicrobials.

METHODS: A historical cohort study of medical records of adult patients admitted to a general and public hospital from May 2010 to July 2011. A cohort was formed with patients admitted in the period before the restrictive measure for the commercialization of antimicrobials (Phase I) and a second cohort was formed with patients admitted after the implementation of the restrictive measure (Phase II).

Correspondence:

Josiane Moreira da Costa

Rua Avenida Antônio Carlos, 6627

Campus Pampulha

31270-901 Belo Horizonte,

MG, Brasil

E-mail: josycostta2@yahoo.com.br

Received: Apr 15, 2018

Approved: Oct 6, 2018

How to cite: Costa JM, Moura CS, Menezes de Pádua CA, Vegi ASF, Magalhães SMS, Rodrigues $M B$, et al. Restrictive measure for the commercialization of antimicrobials in Brazil: results achieved. Rev Saude Publica. 2019;53:68.

Copyright: This is an open-access article distributed under the terms of the Creative Commons Attribution License, which permits unrestricted use, distribution, and reproduction in any medium, provided that the original author and source are credited.

RESULTS: The instantaneous risk of hospital infection by a resistant microorganism was estimated at seven by 1,000 people-time (95\%CI 0.006-0.008) in Phase I, and four by 1,000 people-time (95\%CI 0.003-0.005) in Phase II of the study. The differences between the survival curves in the different phases of the study and stratified by age group were also significant $(\mathrm{p}<0.05)$.

CONCLUSIONS: The results suggest that the implementation of the restrictive measure of the commercialization of antimicrobials by the National Health Surveillance Agency reduced the incidence of hospital infection by a resistant microorganism.

DESCRIPTORS: Anti-Bacterial Agents. Prescription Drug Overuse, legislation \& jurisprudence. Drug Resistance, Microbial. Drug Monitoring. Pharmacovigilance 


\section{INTRODUCTION}

Bacterial resistance to antimicrobials (ATM) poses a serious threat to global public health. Despite its multifactorial genesis, one of the main factors that triggers it is the unnecessary and abusive use of ATM, a fact extensively described in the international and national literature ${ }^{1-4}$.

Resistance can decrease the effectiveness of ATM, requiring the administration of second line drugs, which are usually more toxic and costly, causing damage to the patient and increasing the hospitalization time and expenses for the individual and for the health system ${ }^{5,6}$.

Specific characteristics of developing countries favor the occurrence of microbial resistance in these places, such as low hygiene conditions, poor living conditions, poor quality of medications and access to the parallel market of $\mathrm{ATM}^{7}$. An increase in the consumption of ATM in emerging countries is identified, with Brazil being among the five countries with the highest indices between 2000 and $2010^{8}$. Studies on microbial resistance published in the country so far present incipient data ${ }^{9}$, but show expressive increase in the resistance of these organisms and, consequently, increased morbidity and mortality and the cost of infections ${ }^{10,11}$.

Microbial resistance can be developed by selective pressure resulting from exposure to ATM and from the exchange of genetic material among several species of microorganisms. In this context, exposure to ATM is a fundamental factor in the selection of resistant species. Among the strategies to minimize the development of resistance, the reduction of the prescription of ATM and the implementation of strategies that stimulate rational use at Community level or in hospitals have deserved prominence ${ }^{5,6,12}$. The optimization ${ }^{a}$ of the use of ATM is among the five objectives of the Global Action Plan of the World Health Organization (WHO) to control microbial resistance ${ }^{13}$, in order to reduce the supply and overprescription of antibiotics for human and veterinary use, as well as to strengthen the regulation of its use worldwide. In Brazil, up to 2010 the ATM could be acquired only with the presentation of the prescription, limiting the supervision and favoring self-medication. The collegiate board of the National Health Surveillance Agency (ANVISA), through RDC 44, published on October 26, 2010, in its Art. 2nd determined that prescribed antibiotics can only be dispensed with special control prescription, aiming to restrict the free access to these drugs and minimize the occurrence of microbial resistance ${ }^{14}$.

Inadequate use of ATM at Community level contributes to the selection of resistant strains and dissemination of resistance genes ${ }^{15}$. Since studies indicate that its use in hospitals affects the community microbial resistance and vice vers $\mathrm{a}^{4,16,17}$, it is relevant to evaluate the impact of the implementation of restrictive measures for the marketing of these medicines in both environments.

In the literature, scientific publications indicate the influence of the restrictive measure in the consumption of ATM in Brazil ${ }^{18,19}$, but no publications were identified on the impact of this measure on the reduction of microbial resistance in the hospital environment. Given this context that hospital infections raise health expenditures and cause harm to patients, our study aimed to compare the occurrence of microbial resistance in a hospital environment before and after the implementation of the restrictive measure of ANVISA for the commercialization of ATM in Brazil.

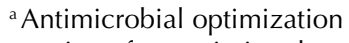
consists of prescription through effective, fast and inexpensive diagnostic techniques, in addition to the prescription and regulation based on evidence and effective regulation and control techniques ${ }^{13}$.

\section{METHODS}

\section{Study Design, Location and Population}

This is a historical cohort study including adult patients admitted to the Hospital Risoleta Tolentino Neves (HRTN) in the period from May 2010 to July 2011. HRTN is a general public 
emergency hospital that has about 330 beds, being a reference for the northern region of Belo Horizonte and neighboring municipalities. Approximately 10,000 patients are attended each month, most are attended in the emergency room and about $13.0 \%$ of the patients are hospitalized in the same institution.

We included patients over 18 years of age, for whom culture exams were requested due to suspected hospital infection or routine procedures to identify bacterial colonization. Patients with diagnosis of bacterial infection at admission or up to 72 hours after hospitalization, women hospitalized for childbirth and puerperium, and patients transferred from another hospital or with length of stay of less than 72 hours were excluded.

This study consisted of two cohorts: The first included patients admitted to the HTRN from May to October 2010, period before the restrictive measure for the commercialization of ATM (Phase I), and the second was formed by patients admitted between February and July 2011, after the implementation of the measure of ANVISA (Phase II). The option for this period aimed to obtain symmetrical time intervals that minimized the interference of non-controllable factors such as turnover of professionals, shortage of the supply of medications and influence of non-standardization of procedures to conduct the examinations of the institution. The team responsible for controlling infections associated with health care at the institution and the clinical body did not undergo alterations during the study period, but a change was recorded in the laboratory that performed the exams in the HRTN in the second semester of 2011 (period after data collection). No shortage of supply of medications occurred during the study periods.

\section{Definition of Study Variables}

The outcome of interest was infection or hospital colonization by a microorganism resistant to ATM, evidenced by positive results of in vitro culture of microorganisms and result of the sensitivity test to Antimicrobial agents (in vitro antibiogram), interpreted as "resistant" in patients with hospitalization stay exceeding 72 hours $^{20}$. In this study, microbial resistance was defined as the antibiotic resistance from a clinical point of view, considering a higher probability of therapeutic failure when an infection by a given microorganism is treated with a class of antibiotics customarily used in clinical practice ${ }^{21}$, identified by resistance results in the antibiogram.

The predictor variables were the phases of the study (before and after the implementation of the restrictive measure), age (adults $<60$ years old and older adults $\geq 60$ years), sex and risk profile of the patients. In relation to the last variable, the hospital under study has a management process in which patients are classified according to the following clinical risk profiles: critically ill patients (assisted in the polytrauma care sector and in the intensive care center), patients in the medical clinic (usually hospitalized for worsening chronic health problems), surgical patients (requiring surgical intervention), and maternal-infant profile (maternity and pediatrics). As the patients treated in the maternity and pediatrics sectors did not present inclusion criteria, the following risk profiles were considered in the study: critically ill, in the medical clinic and surgical patients. The clinical profile was considered a proxy variable of clinical severity or of performing invasive procedures of greater impact.

We also identified the total number of culture exams requested by the patient, the resistant microorganisms and the resistance profile. The microorganisms were classified as producers of extended spectrum $\beta$-lactamases (ESBL) when the isolate was a producer of extended spectrum $\beta$-lactamase. Those classified as Klebsiella pneumoniae carbapenemase (KPC) were those whose strains were carbapenemase-producing, identified by the positive Hodge Test ${ }^{22}$. Also according to the recommendations of the institutional protocol, the growth of atypical microorganisms and fungi in blood culture was counted as resistance when considering the severity of the clinical consequences of these situations. In case of the result "microbial growth in mixed culture," the examination was repeated. 
The procedures of culture collection in the HRTN occurred in case of clinical suspicion of infection or through the culture of axillary and anophanous swab, whose institutional protocol recommended weekly collection for patients with hospitalization time exceeding 15 days, even without signs or symptoms of infection.

\section{Data Collection and Analysis}

The information on bacterial resistance and predictor variables was collected from secondary data, through the review of the patient's electronic record and the generation of computerized reports.

Regarding the identification of microbial resistance, a computerized report of all the culture exams performed for the patients under study was generated, then the results were checked. In specific cases, the information was complemented with records of the hospital infection control committee on the resistance profile in the institution.

Descriptive analysis of the variables was performed for the study population, with distribution of absolute and relative frequencies and measures of central tendency and variability. Survival curves estimated by the Kaplan-Meier method were used to compare the time until the occurrence of at least one hospital infection record by a resistant microorganism in the two phases of the study. The same method was used to compare differences between the study phases stratified by age group. The free time of the outcome was calculated between the date of hospital admission and the occurrence of the first episode of the outcome of interest, censored by the occurrence of death or by hospital discharge in both phases of the study. The Cox proportional hazards model was used to estimate the incidence density ratio (hazard ratio) for microbial resistance infection (MRI) according to the predictor variables. For all analyses, a $0.05 \%$ significance level was adopted. All analyses were conducted using the Stata statistical software version 13.0.

\section{Ethical Considerations}

The project was approved by the Human Research Ethics Committee of the Federal University of Viçosa (Opinion 176/2012).

\section{RESULTS}

During the study period, 5,178 hospitalizations for 4,786 patients in Phase I and 4,618 hospitalizations for 4,261 patients in Phase II were analyzed. Approximately $53.0 \%$ of the patients were men (52.1\% and 53.0\% in Phases I and II, respectively), with a mean age of $49.2(\mathrm{SD}=20.8)$ years in Phase I and $49.7(\mathrm{SD}=21.2)$ years in Phase II $(\mathrm{p}>0.05$ for sex and age).

From the total of patients monitored in Phase I, culture exams were requested for 922 patients (19.3\%), and 8,149 exams were performed, with an average of 8.8 exams per patient. In Phase II, exams were requested for 684 (14.8\%) patients, and a total of 3,404 exams were performed, corresponding to an average of 5.0 exams per patient.

Of the total tests performed, 1,803 and 1,130 isolates were identified in Phases I and II, respectively. Approximately 1,109 (62\%) isolates in Phase I showed resistance, while in Phase II, resistance was identified in 381 (34\%) isolates. In Table 1, resistant microorganisms are described by phase.

The incidence density of hospital infection by a resistant microorganism (in number of cases per hospitalization/day) was significantly higher in Phase I (7 for 1,000 people-time, 95\%CI 0.006-0.008) compared with Phase II (4 for 1,000 people-time, 95\%CI 0.003-0.005). We observed that the free time of infection by bacterial resistance of $75 \%$ of the study population was 27 days in Phase I and 60 days in Phase II (Figure 1). 
Table 1. Resistance profile of microorganisms by study phase.

\begin{tabular}{|c|c|c|c|}
\hline Resistant microorganism & $\begin{array}{c}\text { Phase I } \\
(n)\end{array}$ & $\begin{array}{c}\text { Phase II } \\
(n)\end{array}$ & Resistance profile \\
\hline Acinetobacter baumannii & 308 & 124 & $\begin{array}{l}\text { Imipenem or Meropenem or Ceftazidime or } \\
\text { Ceftriaxone or Cefotaxime or Cefepime }\end{array}$ \\
\hline Achromobacter sp. & 1 & 0 & $\begin{array}{l}\text { Imipenem or Meropenem or Ceftazidime or } \\
\text { Ceftriaxone or Cefotaxime or Cefepime }\end{array}$ \\
\hline Alcaligenes faecalis & 2 & 0 & ATYPICAL* \\
\hline Candida sp.* & 8 & 9 & ATYPICAL* \\
\hline Citrobacter sp. & 1 & 4 & $\begin{array}{l}\text { Imipenem or Meropenem or Ceftazidime or } \\
\text { Ceftriaxone or Cefotaxime or Cefepime }\end{array}$ \\
\hline $\begin{array}{l}\text { Carbapenemase-producing } \\
\text { Enterobacter aerogenes }\end{array}$ & 1 & 0 & Meropenem and imipenem \\
\hline Enterobacter sp. & 54 & 16 & $\begin{array}{l}\text { Imipenem or Meropenem or Ceftazidime or } \\
\text { Ceftriaxone or Cefotaxime or Cefepime }\end{array}$ \\
\hline Enterococcus sp. & 138 & 21 & Vancomycin \\
\hline Escherichia coli & 20 & 25 & $\begin{array}{l}\text { Ceftazidime or Ceftriaxone or Cefotaxime or Ciprofloxacin } \\
\text { or Levofloxacin or Gatifloxacin or Cefepime }\end{array}$ \\
\hline ESBL-producing Escherichia coli & 11 & 1 & Beta-lactams \\
\hline Geotrichum candidum & 1 & 0 & ATYPICAL* \\
\hline Haemophilus sp. & 1 & 0 & ATYPICAL* \\
\hline Klebsiella sp. & 35 & 12 & $\begin{array}{l}\text { Imipenem or Meropenem or Ceftazidime or } \\
\text { Ceftriaxone or Cefotaxime or Cefepime }\end{array}$ \\
\hline $\begin{array}{l}\text { ESBL-producing Klebsiella } \\
\text { pneumoniae }\end{array}$ & 19 & 0 & Beta-lactams \\
\hline $\begin{array}{l}\text { Carbapenemase-producing } \\
\text { Klebsiella pneumoniae }\end{array}$ & 5 & 2 & Beta-lactams \\
\hline Morganella morganii & 5 & 4 & $\begin{array}{l}\text { Imipenem or Meropenem or Ceftazidime or } \\
\text { Ceftriaxone or Cefotaxime or Cefepime }\end{array}$ \\
\hline Proteus mirabilis & 23 & 53 & $\begin{array}{l}\text { Imipenem or Meropenem or Ceftazidime or } \\
\text { Ceftriaxone or Cefotaxime or Cefepime }\end{array}$ \\
\hline ESBL-producin Proteus mirabilis & 0 & 3 & Beta-lactams \\
\hline Providencia stuartii & 2 & 3 & $\begin{array}{l}\text { Imipenem or Meropenem or Ceftazidime or } \\
\text { Ceftriaxone or Cefotaxime or Cefepime }\end{array}$ \\
\hline Pseudomonas aeruginosa & 133 & 46 & $\begin{array}{l}\text { Ciprofloxacin or Levofloxacin or Imipenem or } \\
\text { Meropenem or Ceftazidime or Piperacillin or Cefepime }\end{array}$ \\
\hline Salmonella group & 1 & 0 & ATYPICAL* \\
\hline Serratia sp. & 11 & 3 & $\begin{array}{l}\text { Imipenem or Meropenem or Ceftazidime or } \\
\text { Ceftriaxone or Cefotaxime or Cefepime }\end{array}$ \\
\hline Sphingomonas paucimobilis* & 2 & 0 & Sulfamethoxazole + Trimethoprim \\
\hline Staphylococcus aureus & 228 & 10 & Oxacillin \\
\hline Staphylococcus sp. & 21 & 17 & Oxacillin \\
\hline Staphylococcus epidermidis & 33 & 19 & Oxacillin \\
\hline Staphylococcus haemolyticus & 23 & 6 & Oxacillin \\
\hline Coagulase-negative staphylococcus & 8 & 3 & Oxacillin \\
\hline Stenotrophomonas maltophilia* & 5 & 0 & Sulfamethoxazole + Trimethoprim \\
\hline $\begin{array}{l}\text { Streptococcus agalactiae (beta- } \\
\text { hemolytic) of group B }\end{array}$ & 3 & 0 & $\begin{array}{l}\text { Penicillin or Ceftazidime or Ceftriaxone or Cefotaxime } \\
\text { or Cefepime }\end{array}$ \\
\hline Streptococcus pneumoniae & 1 & 0 & $\begin{array}{l}\text { Penicillin or Ceftazidime or Ceftriaxone or Cefotaxime } \\
\text { or Cefepime }\end{array}$ \\
\hline Streptococcus pyogenes & 2 & 0 & $\begin{array}{l}\text { Penicillin or Ceftazidime or Ceftriaxone or Cefotaxime } \\
\text { or Cefepime }\end{array}$ \\
\hline $\begin{array}{l}\text { Non-pneumococcus Streptococcus } \\
\text { sp. (alpha-hemolytic) }\end{array}$ & 3 & 0 & $\begin{array}{c}\text { Penicillin or Ceftazidime or Ceftriaxone or Cefotaxime } \\
\text { or Cefepime }\end{array}$ \\
\hline Total resistants & 1,109 & 381 & \\
\hline
\end{tabular}

ESBL: Extended spectrum beta-lactamase

* Microorganisms considered atypical because they are not incorporated into the hospital microbiota. According to the institutional protocol, they are counted as resistant, considering the severity of the clinical consequences of infections and the need to implement surveillance strategies to prevent future infections by these pathogens. As to fungi, they were counted as resistant in cases of blood infections. 


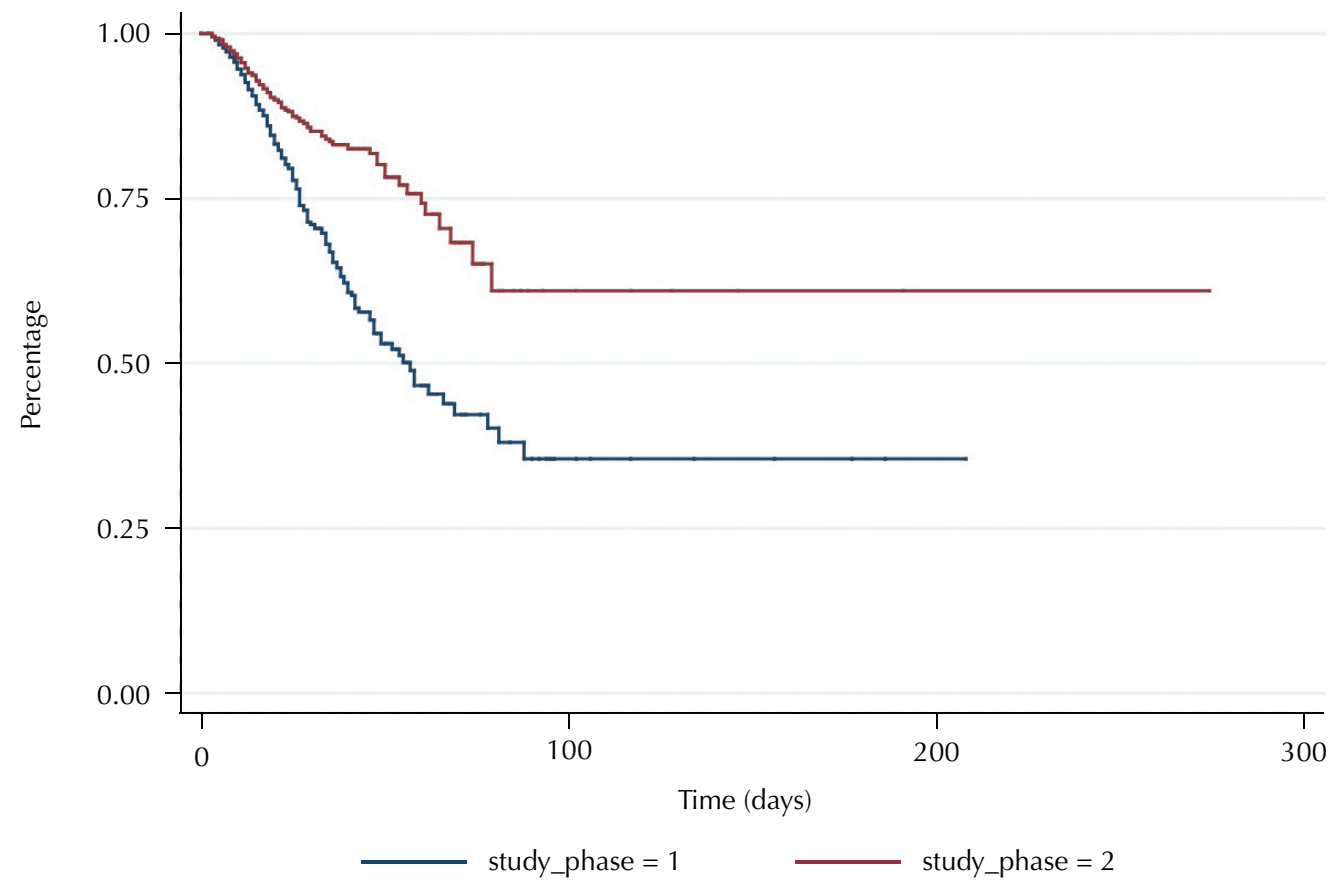

Figure 1. Survival curve free from microbial resistance for hospitalized patients. Belo Horizonte, MG, 2010-2011.

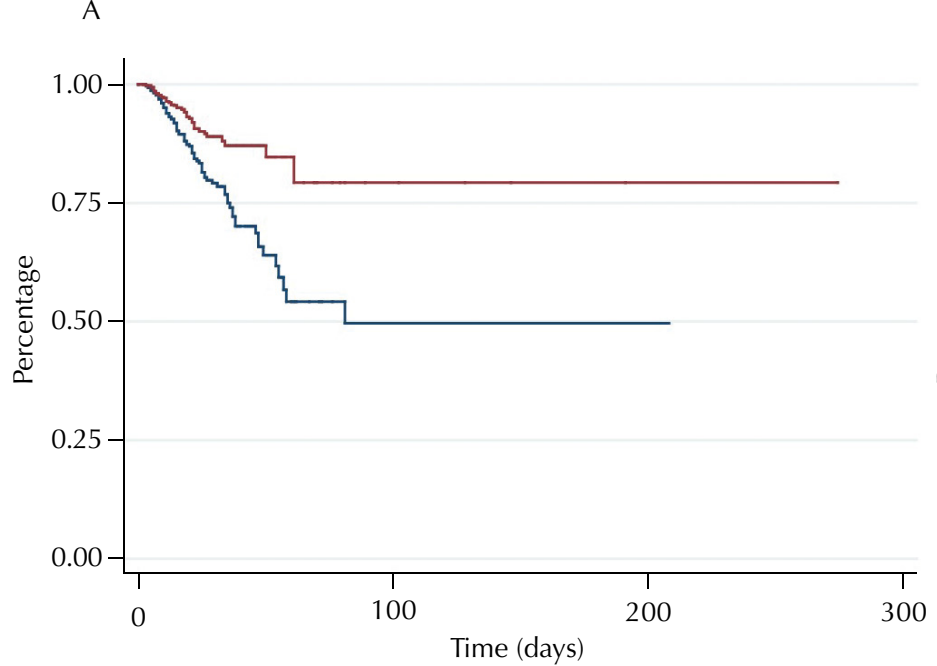

- study_phase $=1 \longrightarrow$ study_phase $=2$

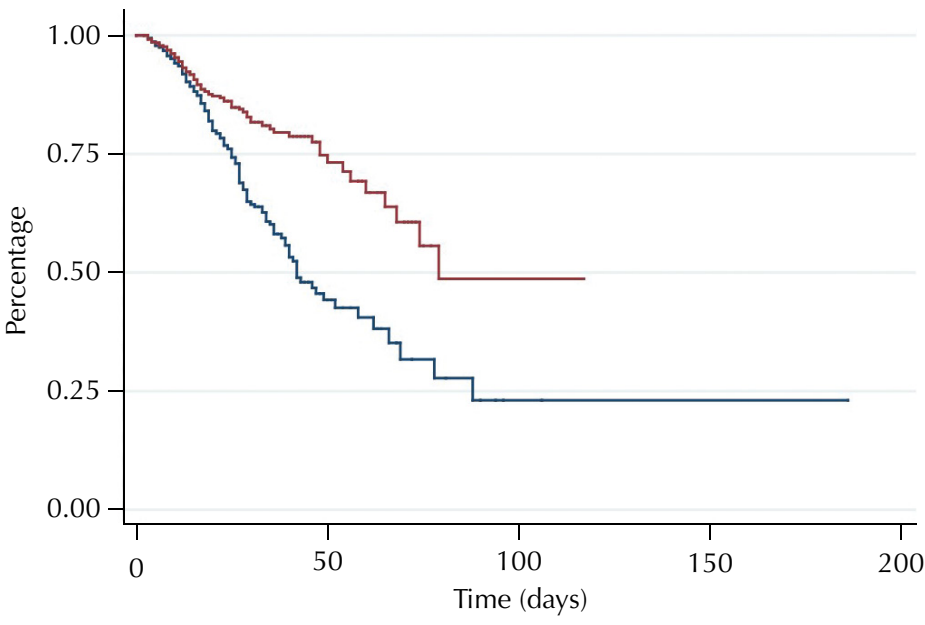

study_phase $=1 \longrightarrow$ study_phase $=2$

Figure 2. Survival curve free from microbial resistance for (A) adult patients and (B) hospitalized older adults. Belo Horizonte, MG, $2010-2011$.

In the stratified analysis by age group, differences were found between the instantaneous risk in the study phases for both groups (Log-rank, $\mathrm{p}<0.05$ ). In adults, the instantaneous risk was five for 1,000 people-time (95\%CI 0.004-0.006) in Phase I and three for 1,000 people-time (95\%CI 0.002-0.004) in Phase II. In older adults (60 years or more), in Phase I it was 0.010 (95\%CI 0.008-0.011) and in Phase II it was 0.006 (95\% CI 0.005-0.007). The free time of MRI in $75 \%$ of the adults was 36 days in Phase I, while in Phase II the outcome was observed in less than $25 \%$ of them. The free time of MRI in $75 \%$ of the older adults was 25 and 48 days in Phases I and II, respectively. In both age groups, the differences in the free time of MRI between the phases were statistically significant (Figure 2). The free time of MRI was lower in Phase I compared with Phase II for those in the medical clinic, surgical and critically ill profiles (Log-rank, $\mathrm{p}<0.05$ ) (Figure 3). 

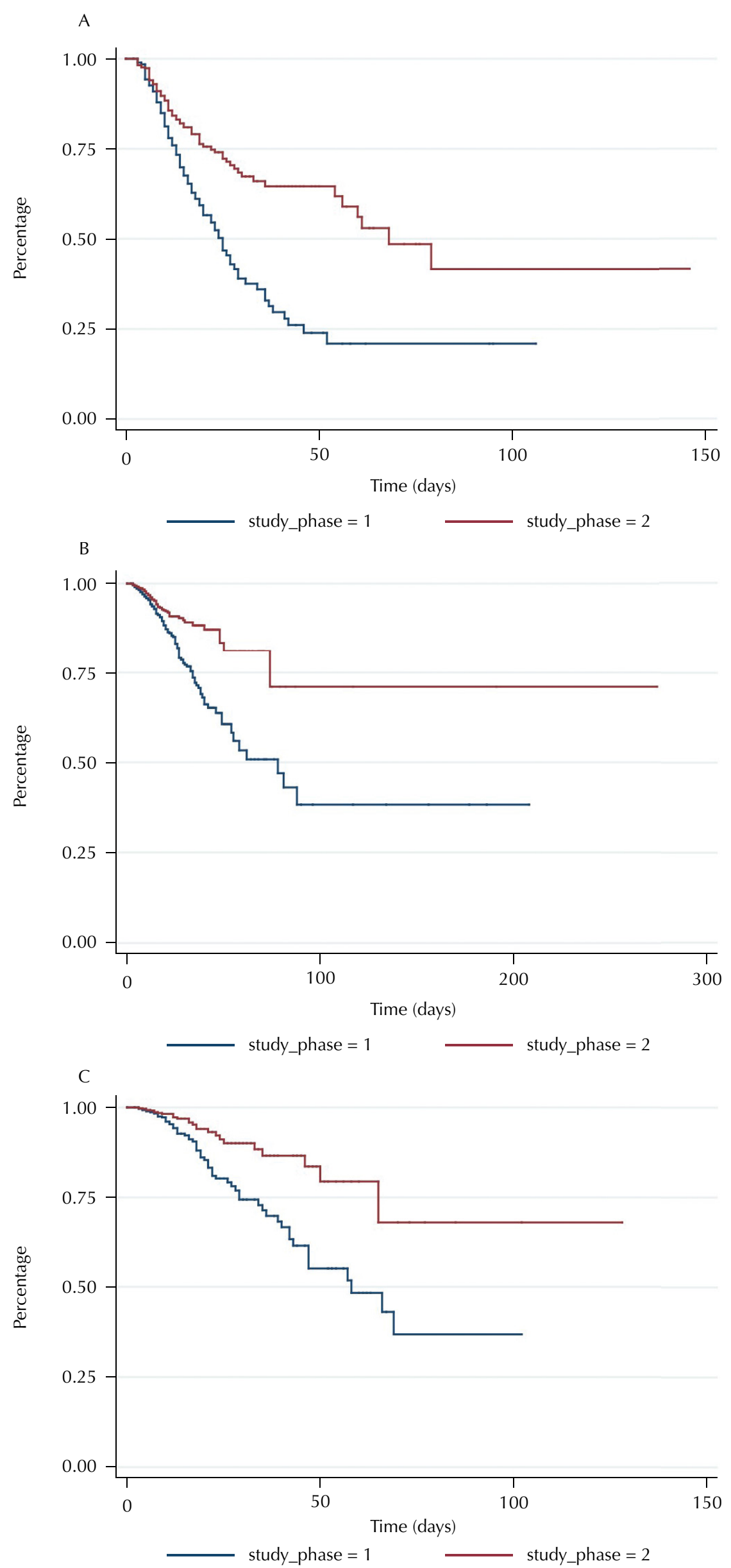

Figure 3. Survival curve free from microbial resistance for (A) critically ill, (B) in the medical clinic and (C) surgical patients. Belo Horizonte, MG, 2010-2011. 
Table 2. Final model of the association between study phase, age, risk profile and MRI. Belo Horizonte, MG, 2010-2011.

\begin{tabular}{|c|c|c|}
\hline \multirow{2}{*}{ Variable } & \multicolumn{2}{|c|}{ HR $(95 \% \mathrm{Cl})$} \\
\hline & Unadjusted $(95 \% \mathrm{Cl})$ & Adjusted* \\
\hline \multicolumn{3}{|l|}{ Study phase } \\
\hline I & 1.0 & 1.0 \\
\hline II & $0.54(0.45-0.65)$ & $0.46(0.39-0.56)$ \\
\hline \multicolumn{3}{|l|}{ Age group (years) } \\
\hline Adult $(<60)$ & 1.0 & 1.0 \\
\hline Older adult $(\geq 60)$ & $1.64(1.37-1.97)$ & $1.56(1.30-1.88)$ \\
\hline \multicolumn{3}{|l|}{ Risk profile } \\
\hline Critically ill patients & 1.0 & 1.0 \\
\hline Medical clinic & $0.33(0.27-0.40)$ & $0.29(0.23-0.35)$ \\
\hline Surgical clinic & $0.36(0.28-0.46)$ & $0.34(0.27-0.44)$ \\
\hline
\end{tabular}

HR: hazard ratio; MRI: microbial resistance infection

$*$ adjusted for study phase and age group.

In the multivariate analysis, we found that age, study phase and risk profile remained independently associated with the risk of MRI. Controlling by age and risk profile, the risk of MRI in Phase II was approximately 50\% lower than the same risk in Phase I (Table 2).

\section{DISCUSSION}

This study shows the contributions of the restrictive measure in reducing the incidence density of nosocomial infections in a population of older patients in a general hospital in Brazil, even after adjusting for age. These findings are important to the scientific literature, considering that, although this measure was adopted in 2010, little is known about its impact on microbial resistance in the hospital environment.

Few Brazilian studies have been conducted in order to identify the contributions of the restrictive measure in the control of infections, and most of them are directed to the analysis of the sales of ATM in drugstores and decrease in the resistance in the community environment ${ }^{18,19}$. We understand that one of the intuitiveness of the measure was also the decrease in the occurrence of microbial resistance in the hospital environment and we believe that the results of this study have an innovative character.

This study showed that the restriction to the community use of ATM can reduce hospital infections by resistant microorganisms. In a hospital environment, microbial resistance is aggravated by different factors, such as fragility of patients' health conditions and proximity to beds, which facilitates the dissemination of cross-Infection ${ }^{5}$. To understand the interference of the community use of ATM in this process favors the implementation and improvement of preventive actions, such as the determination of control over the sale of ATM normalized by ANVISA through RDC 44/2010 ${ }^{14}$.

The results obtained are not restricted to a single hospitalization unit, but comprise different clinics of a large teaching hospital, representing a diversified spectrum of health conditions that differentiate patients from the susceptibility to MRI.

The criterion used to define infection as of hospital nature was its registration in a period equal to or greater than 72 hours of hospital stay, in order to exclude cases of community infection. This criterion is defined in Brazil by Ordinance 2,616 of May 12, $1998^{21}$ and has been adopted in different studies ${ }^{23,24}$. It is not possible to guarantee that some cases detected have not been originated in the community. 
According to our results, the risk of MRI was lower in the post-implementation phase of the restrictive measure, even after adjusting for age. This scenario suggests a reduction or greater adequacy of the prescription of ATM in the community, which may have been reflected in the cited hospital in the second phase of the study. However, studies indicate that, although the implementation of strategies to reduce the consumption of ATM is beneficial and can reduce bacterial resistance ${ }^{16}$, the decrease in consumption may not mean a decrease in infections by multidrug-resistant microorganisms, which should also involve the rational prescription and the decrease in the consumption of specific classes of $\mathrm{ATM}^{16,17}$. Additionally, changes in the behavior of health professionals regarding preventive measures of hospital infection may have occurred simultaneously with the reduction in the use of ATM, contributing to the reduction in MRI. In the analyzed period, no records or reports of restructuring or drastic changes were identified in the routines of the hospital control and infection commission in a study that justified the reduction in the internal consumption of ATM. Presuming that this assumption is valid, the influence of the immediate impact of ANVISA's resolution on the rationalization of the use of ATM and the adoption of measures to prevent hospital infection in Phase II should be considered.

Several studies indicate the abusive use, without indication and in inadequate doses as potentiator of the emergence of strains of microorganisms resistant to $\mathrm{ATM}^{5,25,26}$. However, it is noteworthy that the actions to control and decrease infections by resistant microorganisms are complex and should contemplate not only the restriction of the sale of ATM through medical prescription, but other strategies not addressed in RDC 44/2010, such as the implementation of educational practices for rational prescription, elaboration and implementation of protocols, supervision of prescriptions, hand sanitization campaigns, monitoring and health education to patients to guarantee rational use, control of animal and environmental use, among others ${ }^{4,17,27}$. These measures should be carried out not only at community level but also in the hospital. This reinforces the need for continuous assessments of drug regulatory measures, aiming at the sustainability of MRI reduction. Although the reduction in the acquisition of antimicrobials after RDC 44 was not homogeneous throughout the country, the region where the study was conducted was the one with the largest decrease $\mathrm{e}^{18}$.

The limitations of this study include the impossibility of identifying the association between the reduction in crop collection in the analyzed times and the reduction in infections or colonizations by resistant microorganisms; the short analysis time; the impossibility of using the statistical analysis "interrupted time series," which would be more adequate to analyze dependent samples in sequential phases in time; and the use of few control variables. Although the period to assess the impact of the restriction on the sale of antimicrobials on microorganisms of nosocomial origin may seem short, a systematic review and meta-analysis indicate the occurrence of microbial resistance between one and six months after the use of $\mathrm{ATM}^{28}$, which corroborates our findings.

Our study identified that the anterior and posterior phases to the restrictive measure are independently associated with the reduction of microbial resistance. This is the first investigation in Brazil suggesting the influence of restrictive measures on the reduction of this type of infection in the hospital environment. Therefore, other studies with the objective of monitoring the rates of resistance incidence and the sustainability of the restrictive measure must be conducted.

\section{REFERENCES}

1. Del Fiol FS, Lopes LC, Toledo MI, Barberato-Filho S. Perfil de prescrições e uso de antibióticos em infecções comunitárias. Rev Soc Bras Med Trop. 2010;43(1):68-72. https://doi.org/10.1590/S0037-86822010000100015

2. World Health Organization. Antimicrobial resistance: global report on surveillance. Geneva: WHO; 2014 [cited 2018 Aug 12]. Available from: http://apps.who.int/iris/handle/10665/112642 
3. Senadheera GP, Sri Ranganathan S, Patabendige G, Fernando GH, Gamage D, ManekeRM, et al. Resistance and utilisation pattern of antibacterial agents in outpatient settings in two Teaching Hospitals in Colombo. Ceylon Med J. 2016;61(3):113-7. https://doi.org/10.4038/cmj.v61i3.8346

4. Roca I, Akova M, Baquero F, Carlet J, Cavaleri M, Coenen S, et al. The global threat of antimicrobial resistance: science for intervention. New Microbes New Infect. 2015;6:22-9. https://doi.org/10.1016/j.nmni.2015.02.007

5. Zimerman R. Uso indiscriminado de antimicrobianos e resistência microbiana. Brasília, DF:OPAS Brasil; 2010 [cited 2018 Aug 12]. (Uso racional de medicamentos: temas selecionados; n. 3). Available from: https://www.paho.org/bra/index.php?option=com_docman\& view $=$ document\&layout $=$ default\&alias $=1315$-uso-indiscriminado-antimicrobianos-e-resistenciamicrobiana-uso-racional-medicamentos-temas-selecionados-n-3-5\&category_slug=assistenciafarmaceutica-958\&Itemid=965

6. Macgowan AP; BSAC Working Parties on Resistance Surveillance. Clinical implications of antimicrobial resistance for therapy. J Antimicrob Chemother. 2008;62 Suppl 2:ii105-14. https://doi.org/10.1093/jac/dkn357

7. Padget $M$, Guillemot D, Delarocque-Astagneau E. Measuring antibiotic consumption in low-income countries: a systematic review and integrative approach. Int J Antimicrob Agents. 2016;48(1):27-32. https://doi.org/10.1016/j.ijantimicag.2016.04.024

8. Van Boeckel TP, Gandra S, Ashok A, Caudron Q, Grenfell BT, Levin SA, et al. Global antibiotic consumption 2000 to 2010: an analysis of national pharmaceutical sales data. Lancet Infect Dis. 2014;14(8):742-50. https://doi.org/10.1016/S1473-3099(14)70780-7

9. Ministério da Saúde (BR), Agência Nacional de Vigilância Sanitária. Projeto de implantação da rede nacional de monitoramento da resistência microbiana em serviços de saúde. Termo de Cooperação Anvisa/OPAS. Brasília, DF: Anvisa; 2005 [cited 2018 Aug 10]. Available from: http://www.anvisa.gov.br/servicosaude/hsentinela/projeto_rede_microbiana.pdf

10. Garcia PG, Silva VL, Diniz CG. Occurrence and antimicrobial drug susceptibility patterns of commensal and diarrheagenic Escherichia coli in fecal microbiota from children with and without acute diarrhea. J Microbiol. 2011;49(1):46-52. https://doi.org/10.1007/s12275-011-0172-8

11. Carvalho KS, Mamizuka EM, Gontijo Filho PP. Methicillin/Oxacillin-resistant Staphylococcus aureus as a hospital and public health threat in Brazil. Braz J Infect Dis. 2010;14(1):71-6. https://doi.org/10.1016/S1413-8670(10)70014-3

12. Podolsky SH, Powers JH 3rd. Regulating antibiotics in an era of resistance: the historical basis and continued need for adequate and well-controlled investigations. Ann Intern Med. 2015;163(5):386-8. https://doi.org/10.7326/M15-0802

13. World Health Organization. Global action plan on antimicrobial resistance. Geneva: WHO; 2015 [cited 2018 Aug 10]. Available from: http://www.who.int/antimicrobial-resistance/globalaction-plan/en/

14. Ministério da Saúde (BR), Agência Nacional de Vigilância Sanitária. Resolução da Diretoria Colegiada-RDC No 44, de 26 de outubro de 2010. Dispõe sobre o controle de medicamentos à base de substâncias classificadas como antimicrobianos, de uso sob prescrição médica, isoladas ou em associação e dá outras providências. Brasília, DF: Anvisa; 2010 [cited 2018 Aug 10]. Available from: http://bvsms.saude.gov.br/bvs/saudelegis/anvisa/2010/ res0044_26_10_2010.html

15. Abrantes PM, Magalhães SMS, Acurcio FA, Sakurai E. A qualidade da prescrição de antimicrobianos em ambulatórios públicos da Secretaria Municipal de Saúde de Belo Horizonte, MG. Cienc Saude Coletiva. 2008;13 Supl:711-20. https://doi.org/10.1590/S1413-81232008000700021

16. Lawes T, Lopez-Lozano JM, Nebot CA, Macartney G, Subbarao-Sharma R, Dare CR, et al. Effects of national antibiotic stewardship and infection control strategies on hospital-associated and community associated meticillin-resistant Staphylococcus aureus infections across a region of Scotland: a non-linear time-series study. Lancet Infect Dis. 2015;15(12):1438-49. https://doi.org/10.1016/S1473-3099(15)00315-1

17. Kardas-Sloma L, Boëlle PY, Opatowski L, Guillemot D, Temime L. Antibiotic reduction campaigns do not necessarily decrease bacterial resistance: the example of methicillinresistant Staphylococcus aureus. Antimicrob Agents Chemother. 2013;57(9):4410-6. https://doi.org/10.1128/AAC.00711-13 
18. Moura ML, Boszczowski I, Mortari N, Barrozo LV, Neto FC, Lobo RD, et al. The impact of restricting over-the-counter sales of antimicrobial drugs. Medicine (Baltimore). 2015;94(38):e1605. https://doi.org/10.1097/MD.0000000000001605

19. Mattos KPH, Visacri MB, Quintanilha JCF, Lioret GR, Cursino MA, Levin AS, et al. Brazil's resolutions to regulate the sale of antibiotics: impact on consumption and Escherichia coli resistance rates. J Glob Antimicrob Resist. 2017;10:195-9. https://doi.org/10.1016/j.jgar.2017.05.023

20. Ministério da Saúde (BR). Portaria № 2.616 de 12 de maio de 1998. Dispõe sobre o controle de infecções hospitalares. Brasília, DF; 1998 [cited 2018 Jul 20]. Available from: http://bvsms. saude.gov.br/bvs/saudelegis/gm/1998/prt2616_12_05_1998.html

21. Martinez JL. General principles of antibiotic resistance in bacteria. Drug Discov Today Technol. 2014;11:33-9. [cited 2018 Jul 20]. Available from: https://doi.org/10.1016/j.ddtec.2014.02.001

22. Tamma PD, Simner PJ. Phenotypic detection of carbapenemase-producing organisms from clinical isolates. J Clin Microbiol. 2018;56(11):1-28. https://doi.org/10.1128/JCM.01140-18

23. Forster AJ, Taljaard M, Oake N, Wilson K, Roth V, Walraven C. The effect of hospital-acquired infection with Clostridium difficile on length of stay in hospital. CMAJ. 2012;184(1):37-42. https://doi.org/10.1503/cmaj.110543

24. Mladenovic-Antic S, Kocic B, Velickovic-Radovanovic R, Dinic M, Petrovic J, Randjelovic $\mathrm{G}$, et al. Correlation between antimicrobial consumption and antimicrobial resistance of Pseudomonas aeruginosa in a hospital setting: a 10-year study. J Clin Pharm Ther. 2016;41(5):532-7. https://doi.org/10.1111/jcpt.12432

25. Garcia LM, César ICO, Braga CA, Souza GAAD, Mota EC. Perfil epidemiológico das infecções hospitalares por bactérias multidrogarresistentes em um hospital do norte de Minas Gerais. Rev Epidemiol Control Infect. 2013;3(2):45-9. https://doi.org/10.17058/reci.v3i2.3235

26. Higuera-Llantén S, Vásquez-Ponce F, Barrientos-Espinoza B, Mardones FO, Marshall SH, Olivares-Pacheco J. Extended antibiotic treatment in salmon farms select multiresistant gut bacteria with a high prevalence of antibiotic resistance genes. PLoS One. 2018;13(9):e0203641. https://doi.org/10.1371/journal.pone.0203641

27. Sakeena MHF, Bennett AA, McLachlan AJ. Enhancing pharmacists' role in developing countries to overcome the challenge of antimicrobial resistance: a narrative review. Antimicrob Resist Infect Control. 2018;7:63. https://doi.org/10.1186/s13756-018-0351-z

28. Bryce A, Hay AD, Lane IF, Thornton HV, Wootton M, Costelloe C. Global prevalence of antibiotic resistance in paediatric urinary tract infections caused by Escherichia coli and association with routine use of antibiotics in primary care: systematic review and meta-analysis. BMJ. 2016;352:i939. https://doi.org/10.1136/bmj.i939

Funding: Fundação de Amparo à Pesquisa de Minas Gerais (FAPEMIG - Process APQ-01651-11).

Authors' Contribution: Study conception and planning: JMC, AQR, CAMP, SMSM, CSM. Data collection: MBR. Data analysis and interpretation: JMC, AQR, CAMP, ASFV, CSM. Preparation and writing of the manuscript:JMC, AQR, CAMP, SMSM, ASFV, MBR, CSM. Critical revision of the manuscript: JMC, AQR, CAMP, SMSM, CSM. Final approval: JMC, AQR, CAMP, ASFV, SMSM, MBR, CSM.

Acknowledgements: To Edna Mariléa Meireles Leite, Simony Gonçalves and Débora de Vasconcelos, for contributing to the process of critical discussion of the findings.

Conflict of Interest: The authors declare no conflict of interest. 